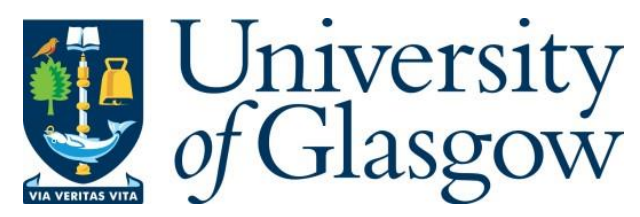

Bikanga Ada, M. and Turinicova, K. (2020) Developing a Dual Dashboard Early Detection System. In: 2020 IEEE 20th International Conference on Advanced Learning Technologies (ICALT), Tartu, Estonia, 06-09 Jul 2020, pp. 155-157. ISBN 9781728160900 .

There may be differences between this version and the published version. You are advised to consult the publisher's version if you wish to cite from it.

http://eprints.gla.ac.uk/237312/

Deposited on: 24 March 2021

Enlighten - Research publications by members of the University of Glasgow http://eprints.gla.ac.uk 


\section{Developing a Dual Dashboard Early Detection System}

\author{
Mireilla Bikanga Ada \\ School of Computing Science \\ University of Glasgow \\ Glasgow, United Kingdom \\ Mireilla.BikangaAda@glasgow.ac.uk
}

\author{
Katarina Turinicova \\ School of Computing Science \\ University of Glasgow \\ Glasgow, United Kingdom \\ Katarina.turinicova@yahoo.com
}

\begin{abstract}
This paper describes the development of 'StudentsAtRisk', a prototype early detection system. It is based on engagement with course materials and can be used to identify students who are falling behind by automatically flagging them. The system also allows instructors to flag these students manually. On their dashboard, students can flag themselves, as engagement with the material might not reveal all those who struggle.
\end{abstract}

Keywords-learning analytics; at-risk student; higher education; early warning systems; early detection systems

\section{INTRODUCTION}

Learning Analytics potential lies in the ability to improve understanding and support of learning processes [1]. Studies suggest that logs of learner activity generated by interaction with online learning systems can be used for predictions of future performance of students [2] and understand student engagement [3]. Logs can be used to detect struggling students as withdrawal from interactions is an early indicator of at-risk behaviour associated with eventual dropping-out or failing. This paper goes through the development and implementation of a web application, 'StudentsAtRisk', which will monitor student engagement in two-week time frames to detect early signs of risk. The rest of the paper is divided as follows: Section II provides the background including a brief overview of similar applications; Section III is concerned with the framework used to develop the system; Section IV gives a brief account of the system architecture; Section V presents a brief conclusion and future work.

\section{BACKGROUND}

Learning analytics aim to model, predict and optimize learning-related processes, environment and decision-making based on static and dynamic information collected about learners and learning environments [4]. This may enable recognition of students at risk of dropping out or those in need of additional support [5].

\section{A. Students at Risk}

Typically, at-risk students are those who are facing the risk of withdrawing from or failing a course. They can be identified using performance metrics, i.e. having received low grades. However, a study conducted by Peterson et al. [6] focusing on understanding the issue of students dropping out from an introductory computing science (CS) course CS1 revealed that the problem starts much earlier. Their work shows that sometimes, students themselves do not realise they have fallen behind in their studies until they have received a failing mark, triggering a vicious cycle of trying to catch up with old material while falling behind with the new one. While there might be support available, Peterson et al. reported that a student in such a situation feels like there is no support. Therefore, to help students overcome this issue, they need to be provided with support on time - as soon as the problem occurs, while consistently promoting effective study behaviour [6]

\section{B. Learner Empowerment}

Most LA systems are used to report data to instructors which can undermine the student's perception of autonomy [7]. Hence, a balanced system intended to serve students and instructors should make both stakeholder groups feel informed and empowered. In this system, data visualisations and reports will also be provided to students to promote students' autonomy and self-control over their learning processes and motivation.

\section{Existing systems}

Course Signals of Purdue University, Indiana is an EWS most discussed by research on LA deployment. Its primary aim is to provide an early intervention tool working on LA predictive models to provide real-time feedback to students, thus improving their success and university retention rate [8]. But it is confusing due to the plurality of feedback options. SEAtS is a cloud-based commercial EWS that has been implemented in 20 UK universities since 2015 [9] and facilitates engagement from the third week. TRANSIT is an open-source EWS script that detects students at risk of failing from the 8th week of starting university [10]. They use both performance and engagement metrics.

The system described in this paper is unique in that, on their dashboard, students can flag themselves as at-risk - no other system offers that functionality.

\section{CROSS-PLATFORM FRAMEWORK}

The system's requirements include a sign-in / login page; calculating which students are at risk; automatically flagging all students who are at risk based on decided specifications; periodically run automatic updates on the flagged students' 
list; allow students to view which courses they are at-risk in; provide a visualization of the analytics performed; enable instructors to manually flag students as at-risk and allow students to self-flag themselves as at-risk.

The full-stack Python framework Django was chosen because it facilitates rapid Web development with pragmatic design principles, offering plenty of build-in web-app features like a dynamic admin interface, it is highly scalable, versatile and secure [11]. In addition, it has an in-built object-relational mapping (ORM) tool which improves the interaction between the object-oriented language and relational databases. The database (DB) systems supported by Moodle are also all relational (Oracle, Postgres, MySQL and MS-SQL). For a visual representation of the analytics, Highcharts were selected because they belong among the best 3 JS chart libraries on the market and unlike the top two selections, they are free for non-commercial users.

\section{SYSTEM ARCHITECTURE}

Figure 1 presents the general architecture of StudentsAtRisk web application. The implementation follows a Django-specific MTV design.

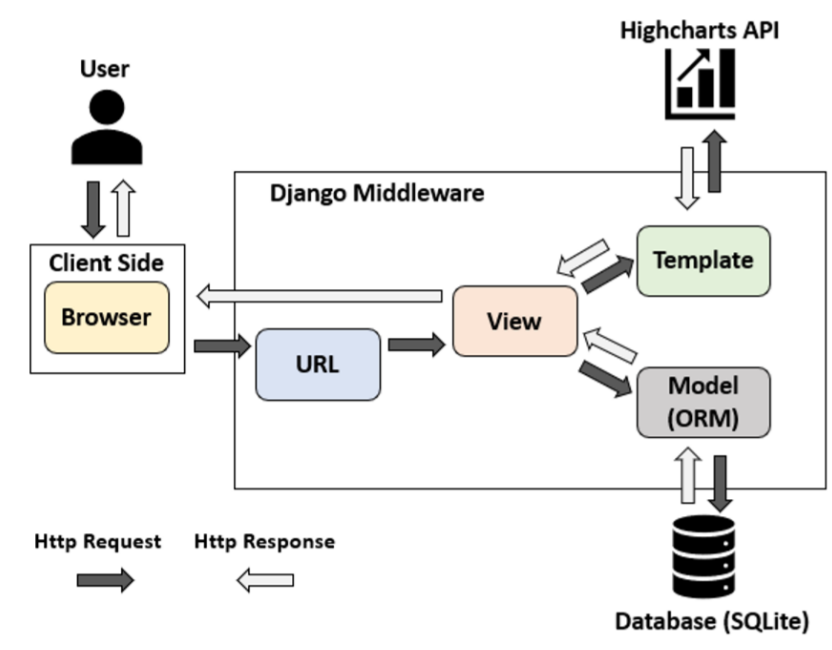

Figure 1. System Architecture

\section{A. Risk Calculation}

Risk status is allocated per course, not per student, and the pre-requisite for risk assignment is for a student to have had no interaction or engagement with any of the course material types available for the specific course. However, measuring the overall 'hits' or 'click' alone would not provide much insight. To improve the effectivity of this engagement metric, it needs to be analysed in a specific, carefully selected time frame. One week would most likely generate numbers of at-risk students disproportionate to reality since the students might have too much other material to study for a particular week and thus disregard studies for another subject, or they might not study for a subject they consider easy on a weekly basis, whereas setting the time frame to three weeks would signify three weeks of zero interaction with any material related to a particular course, causing this time frame to catch risk signs later than sooner. Thus, two weeks are stipulated to achieve the desired effect.

\section{B. User Interface}

On the student dashboard (Figure 2), the graph shows course-specific engagement statistics. The red panel lists the courses a student is at risk at, and the yellow panel on the right offers the self-flagging functionality. After a student flags himself/herself, jQuery updates the flagged courses list and displays a success message below the help button (Figure 3)

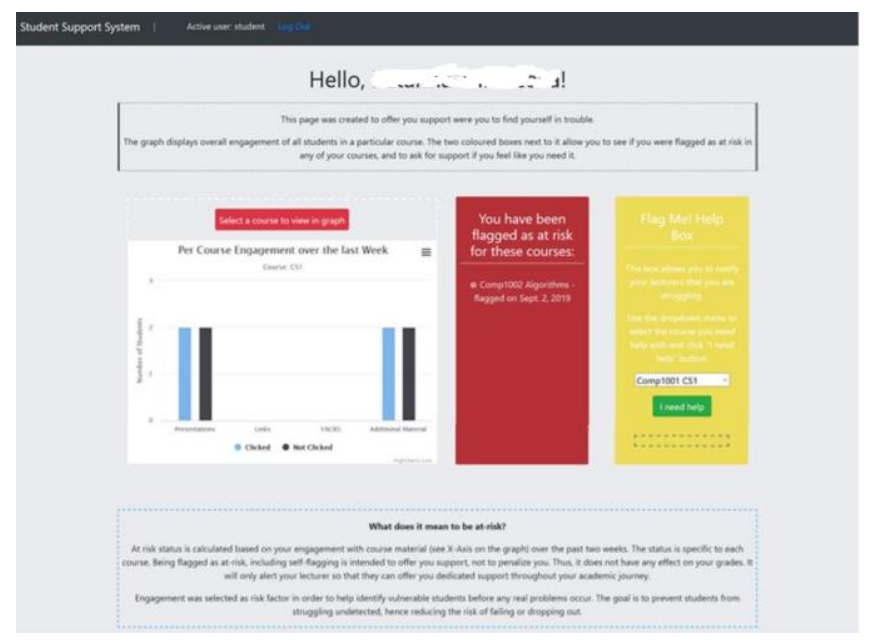

Figure 2. Student panel

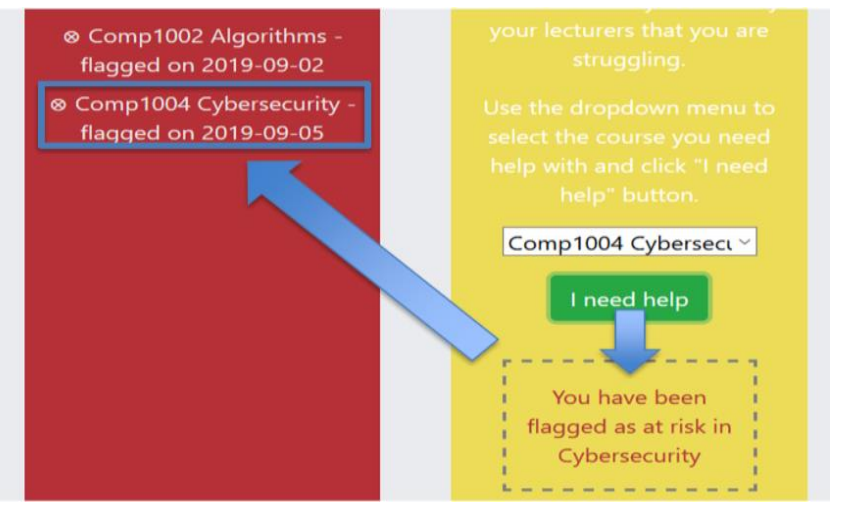

Figure 3. Sefl-flagging

On the instructors' panel (Figure 4), each graph entails interactive functionality whereby a user can hover on a specific point on a graph to reveal a small pop-up window specifying the data pertinent to that point. Furthermore, the top-right corner of each graph includes a menu bar. When 
opened, a user is presented with several further functionalities that support the goal of LA. They can open the graph in full-screen mode, download the graph as an image, PDF or a vector file, or download the graph's data in a .csv or .xls file. The instructor can alter between viewing only students at risk and all students, all the while having the option of changing the risk status of students. Moreover, the instructor can see students who flagged themselves (Figure 5). An instructor can search for all students on a specific course, or for all courses a particular student is enrolled in. The table is organised by date flagged so the new at-risk students can be noticed immediately, hence improving the provision of timely support.

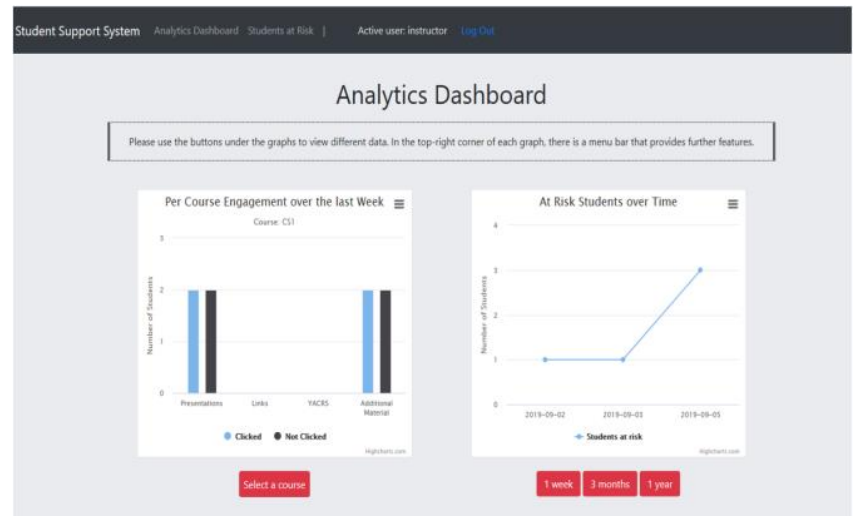

Figure 4. Instructor's panel

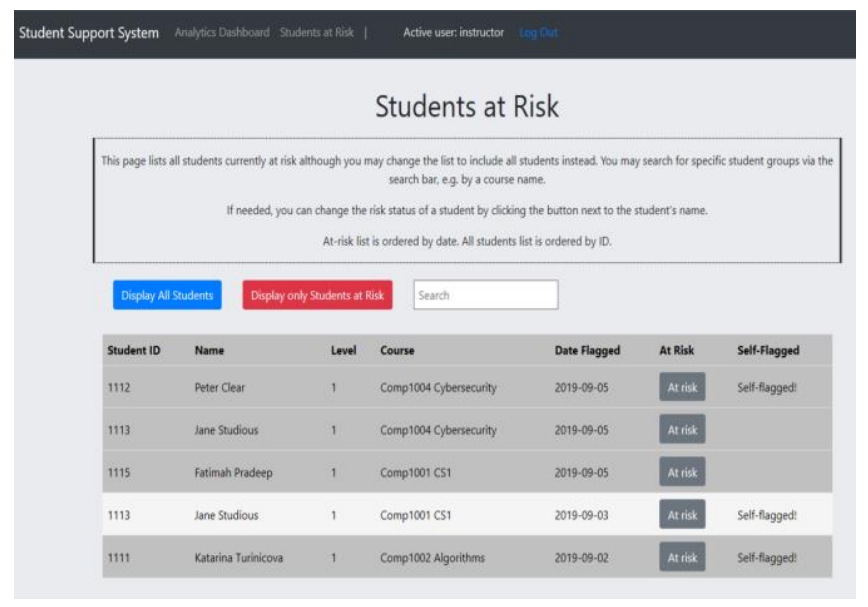

Figure 5. Instructor's Student at risk panel

\section{CONCLUSION}

This paper presented a prototype web application, StudentsAtRisk that allows the identification of at-risk students. It will enable instructors to monitor students and will also allow students to flag themselves, thus not only giving them more autonomy but improving the chances of students receiving support when needed. Future works will include more parameters for calculating risk, a messaging platform to enhance the instructors' ability to provide support and generating alerts that would be sent to students' e-mail addresses when they get flagged. Finally, an evaluation of the system to show whether it is more predictive of at-risk students than other methods in the literature will follow. A study will be conducted to assess the validity of the 'definition' of at-risk students based on the 'non-clicked' course material.

\section{REFERENCES}

[1] D. Gašević, S. Dawson and G. Siemens. "Let's not forget: Learning analytics are about learning," TECHTRENDS TECH TRENDS vol. 59, pp. 64-71 (2015) doi:10.1007/s11528-014-0822-x

[2] Y-H. Hu, C-L. Lo and S-P. Shih. "Developing early warning systems to predict students' online learning performance". Comput. Hum. Behav. Vol. 36, C (July 2014), pp. 469-478. DOI:https://doi.org/10.1016/j.chb.2014.04.002

[3] M. Bikanga Ada and M. Stansfield, "The Potential of Learning Analytics in Understanding Students' Engagement with Their Assessment Feedback," 2017 IEEE 17th International Conference on Advanced Learning Technologies (ICALT), Timisoara, 2017, pp. 227-229. doi: 10.1109/ICALT.2017.40

[4] D. Ifenthaler. "Learning Analytics," in The SAGE Encyclopedia of Educational Technology, edited by J. M. Spector, ed. LA, California: Sage Publications, 2015, pp. 448-451.

[5] G. Siemens and P. Long. 2011. "Penetrating the fog: Analytics in learning and education," EDUCAUSE review, vol. 46, 5, pp. 31-40. https://er.educause.edu/ /media/files/articledownloads/erm1 151.pdf $\% 20$

[6] A. Petersen, M. Craig, J. Campbell and A. Tafliovich. 2016 "Revisiting why students drop CS1," in Proceedings of the 16th Koli Calling International Conference on Computing Education Research (Koli Calling '16). Association for Computing Machinery, New York, NY, USA, pp. 71-80. DOI:https://doi.org/10.1145/2999541.299955.

[7] B. A. Schwendimann et al., "Perceiving Learning at a Glance: A Systematic Literature Review of Learning Dashboard Research," in IEEE Transactions on Learning Technologies, vol. 10, no. 1, pp. 3041, 1 Jan.-March 2017. doi: 10.1109/TLT.2016.2599522.

[8] K. E. Arnold and M. D. Pistilli. "Course signals at Purdue: using learning analytics to increase student success," in Proceedings of the 2nd International Conference on Learning Analytics and Knowledge (LAK '12). Association for Computing Machinery, New York, NY, USA, pp. 267-270. 2012. DOI:https://doi.org/10.1145/2330601.2330666

[9] SEAtS Software. (2019). Retrieved from https://www.seatssoftware.com/

[10] D. Hope, P. Docherty, T. Bailey, S. M. Rhind, M. J. Cullen, A. Dewar and H. Cameron. "Early Warning System - students at risk of failure". University of Edinburgh. 2016 [online] Retrieved from https://www.ed.ac.uk/institute-academic-development/learningteaching/funding/funding/previous-projects/year/march-2014/earlywarning

[11] Django.

(2019).

Retrieved

from 